\title{
Some Considerations on the Long-Term Prospects of Plasma Markets
}

\author{
Jean Mercier Ythier* \\ Centre de recherche en économie et droit (CRED), Université de Paris Panthéon-Assas, France
}

The economics of blood products has gone through large transformations in recent decades, mainly fostered by the rapid growth in demand for immunoglobulins. The world demand for source plasma from fractionation industries has thus jumped from 16.4 million litres in 1990 to 51.2 million litres in 2016. In the same period, the share of source plasma stemming from altruistic blood donations has dropped from about one third to less than 15 percent. The complement has been provided by paid plasmapheresis (mainly of US origin), the share of which has grown, accordingly, from two thirds in 1990 to over 85 percent now [1].

As a consequence of these changes, the economics of blood products currently has two sharply distinct facets. There are, on the one hand, labile blood products for transfusion, which are produced from altruistic blood donations and which are provided mainly by nonprofit collection organizations. On the other hand, there are plasma-derived products, which are produced mainly by for-profit pharmaceutical industries. The source plasma consumed by the latter is collected principally via remunerated plasmaphereses performed by dedicated for-profit collection centres.

In terms of the normative environment, the non-profit character of blood collection for transfusion has been supported by the World Health Organization (WHO) since its resolution WHA28.72 of 1975 . It is presently supported by law, accordingly, in most of WHO's member states. The market for fractionation plasma, on the contrary, has been widely contested since its emergence on a significant scale in the United States in the late sixties, for ethical reasons involving both objections to the selling of body parts and fluids per se, and the criticism that it involves a form of exploitation of the poor.

The considerable quantitative expansion of this market in the last two decades has brought the intensity of ethical dispute to a peak in recent years. It also has aroused growing stakeholders' concerns about the sustainability of a global market that relies to such a large extent on the supply of source plasma from a narrow population of a couple of million paid donors in the United States. The fragile dynamics of current market expansion are exposed, notably, to three types of basic uncertainties in the long run: (i) The political risk entailed by the intensity of ethical protests against plasma markets, in high-income countries particularly; (ii) The public health risk entailed by the ongoing extension of paid plasmapheresis to a growing number of medium-income countries; and (iii) The economic risk associated with the price volatility of source plasma as a raw material, which could result in the crowding out of the US supply if medium-income countries provide larger and larger quantities at prices below the optimized collection cost of US plasmapheresis centres (i.e. about $\$ 150$ per litre).

In my view, these long-term prospects and uncertainties call for two types of responses, as far as fractionation plasma is concerned.

The first one, applicable to the short and medium term, is simply the renewed recognition of the fact that fractionation plasma, as a raw material, should be subject to specific rules and regulations, on the basis of, both, its human origin and its destination as a basic input for the production of scarce medicines. This calls for the activation of the self-sufficiency objectives recommended by WHO (in its resolution WHA63.12 in particular). A suitable interpretation of these recommendations, topical in countries that have made the choice of free blood donation, such as a number of Western European countries, Canada or Australia for example, could consist of an active public support, for both non-remunerated plasmapheresis and the self-sufficient production of a short list of strategic plasma-derived products.

The second type of response, particularly relevant for the long term, would consist of the development of plasma-saving medical and biomedical substitutes for the "donation-intensive" treatments and techniques presently in use in transfusion medicine. For instance: (i) Recombinant biotechnologies, successfully applied to the production of coagulation factors since the 1990s; (ii) Innovative plasma-free products and

*Corresponding author: Jean Mercier Ythier, Centre de recherche en économie et droit (CRED), Université de Paris Panthéon-Assas, 12, place du Panthéon, 75005 Paris, France

Accepted: April 13, 2020

Published online: April 15, 2020

Citation: Mercier Ythier J (2020) Some Considerations on the Long-Term Prospects of Plasma Markets. J Transplant Surg 3(1):46-47 
processes for immunotherapies (e.g. monoclonal antibodies) and gene therapies, under development, with significant prospects of market availability in the near future; and (iii) In the more distant future, the production of red blood cells and platelets from hematopoietic stem cells, which would not save plasma per se, but would relax the overall pressure on the scarce resources in altruistic blood donation, and would thereby facilitate the development of (non-remunerated) plasmapheresis.

A simple calculation will suffice to illustrate the stakes of the scarcity issue that confronts the plasma economy. Suppose that the third type of biotechnologies above becomes ready to use and cost-effective tomorrow morning, and that the red blood cells and platelets transfused are entirely produced from stem cells from then on. Suppose moreover that the hundred million (or so) free blood donations currently performed worldwide are converted into a hundred million plasmaphereses, and that the European norm of $600 \mathrm{ml}$ per plasmapheresis is applied to them. This would yield a volume of altruistic plasma donations of 60 million litres, that is, a world collection only slightly larger than the current (and still rapidly growing) consumption of the fractionation industry.

Immunoglobulins are the main driver of the current growth in the world demand for fractionation plasma, and there are good reasons to doubt that recombinant technologies can be successfully applied to them (i.e. produce valuable medical substitutes for plasma-derived immunoglobulins). This fact and the simple calculation above suggest that the main route for solving the scarcity issue, if any, could be the second one outlined above, that is, the development of plasma-free immunotherapies and gene therapies.

\section{References}

1. J. Mercier Ythier (2020) The contested market of plasma. Transfusion Clinique et Biologique. 27: 52-57.

DOI: $10.36959 / 338 / 331$ 